\title{
Estado, desarrollo e integración regional en los países del MERCOSUR: dinámicas y balance del ciclo pos-neoliberal 2003-2015
}

\author{
State, Development and Regional Integration in the MERCOSUR \\ countries. Dynamics and balance of post-neoliberal cycle (2003- \\ 2015)
}

\section{Pablo Míguez}

\section{Resumen}

El período pos-neoliberal que en América Latina se extendió desde comienzos del siglo XXI por más de una década muestra signos claros de agotamiento y de una crisis de alternativas preocupante. Los ańos de reflujo del pensamiento y las políticas neoliberales atravesaron a casi todos los países latinoamericanos, donde tuvieron lugar importantes procesos políticos y económicos que, sin embargo, imponen un balance y análisis crítico sobre el grado de profundidad de los mismos y el alcance de la reversión de las políticas y procesos del período neoliberal. Desde 2015 en adelante se asiste a la emergencia de regímenes políticos antagónicos a las experiencias políticas y el ideario distributivo asociado al período pos-neoliberal. En este trabajo repasamos las principales experiencias políticas asociadas a las transformaciones en la dinámica de la acumulación del capital y en las lógicas de intervención del estado en los países del MERCOSUR.

\section{Palabras clave}

MERCOSUR; Estado; Desarrollo; Pos-Neoliberalismo.

\section{Abstract}

The post-neoliberal period - which in Latin America stretched from the beginning of the 21 st century for more than one decade - shows clear signs of exhaustion and a troubling crisis of alternatives. The years of reflux of thought and neo-liberal policies crossed almost all Latin American countries, where took place important economic and political processes that, however, impose a balance and critical analysis of the degree of depth of them and the scope of a reversal of policies and processes of the neoliberal period. From 2015 onwards we are witnessing the emergence of antagonistic political regimes to the political experiences and the distributive ideology associated with the post-neoliberal period. In this work we review the major political experiences associated with the changes in the dynamics of the accumulation of capital and the logic of intervention of the State in MERCOSUR countries.

\section{Keywords}

MERCOSUR; State; Development; Post-Neoliberalism. 


\section{Introducción}

El período pos-neoliberal, que en América Latina se extendió desde comienzos del siglo XXI por más de una década, muestra signos claros de agotamiento y de una crisis de alternativas preocupante. Los ańos de reflujo del pensamiento y las políticas neoliberales atravesaron a casi todos los países latinoamericanos, donde tuvieron lugar importantes procesos políticos y económicos que, sin embargo, imponen un balance y análisis crítico sobre el grado de profundidad de los mismos, puesto que supusieron la consolidación de un modo de acumulación centrado en una nueva inserción del capitalismo doméstico en el mercado mundial sustentada en la producción y exportación de commodities de escaso valor agregado. Desde 2015 en adelante se asiste a la emergencia de regímenes políticos antagónicos a las experiencias políticas del período pos-neoliberal.

En América Latina numerosos procesos políticos como el iniciado por Hugo Chávez en Venezuela, Luis Inácio "Lula" da Silva en Brasil, Néstor Kirchner en Argentina, Evo Morales en Bolivia o Rafael Correa en Ecuador intentaron poner fin a los procesos neoliberales pero sólo parecen haber suspendido sus principales dinámicas, que hoy se ven relanzadas. La caída del gobierno de Dilma Rousseff en 2016 supuso el final de un ciclo de gobiernos de las fuerzas progresistas en Brasil y el anuncio de un cierre de ciclo para los regímenes políticos vigentes en América Latina, que suponen también una crisis del Neodesarrollismo como proyecto de reconstrucción del tejido económico y social.

En este trabajo repasaremos las principales experiencias políticas asociadas a las transformaciones en la dinámica de la acumulación del capital y en las lógicas de intervención del Estado en los países del MERCOSUR, con las limitaciones que ello ha impuesto a las tentativas de transformación de la matriz productiva y de la lógica de integración de la región en el mercado mundial en el inicio del siglo XXI. Como veremos, fueron determinantes para dicha inserción el aumento de los precios de las materias primas, un alejamiento parcial de la esfera de influencia norteamericana sobre América Latina y el posterior ascenso de China como demandante de los commodities de las economías latinoamericanas. Dejemos al margen el análisis de la situación de Venezuela al incorporarse formalmente al Mercosur sobre el final del período analizado y como resultado de consideraciones estratégicas más que económicas, a partir de la creación en 2011 de la Alianza del Pacífico (AP) como una Zona de Libre Comercio entre Chile, Perú, Colombia y México. Se había propuesto su incorporación en 2006 - luego del rechazo al ALCA - pero su ingreso fue sido 
resistido por Paraguay y por la burguesía industrial paulista por lo que se consigue incorporar a Venezuela como miembro pleno del bloque recién en 2012 (KAN, 2014, p. 29). A su vez, Venezuela impulsaba un proyecto de integración propio para América Latina como el ALBA, lo que excede los límites de este trabajo.

\section{Primer momento: el auge "neodesarrollista" en el ciclo ascendente posneoliberal (2003-2013)}

El Neodesarrollismo surge como propuesta de modelo económico a partir del ascenso de los gobiernos de Lula en Brasil y Néstor Kirchner en Argentina. Estimulado por el comienzo de un ciclo alcista inédito de los precios de las materias primas en el mercado mundial, Luis Carlos Bresser Pereira en Brasil y Aldo Ferrer en Argentina, desarrollaron un conjunto de ideas llamadas a "superar la etapa neoliberal" recuperando los planes desarrollistas pero procurando esta vez no reeditar los errores de la Industrialización Sustitutiva de Importaciones (ISI).

Bresser Pereira se preguntaba a comienzos de los años 2000 por las razones que impidieron que América Latina alcanzara los niveles de crecimiento de otras regiones periféricas como las del sudeste asiático, siendo que en los años setenta se encontraban en niveles similares de desarrollo (y que aún en los años ochenta seguían siendo alcanzables). Aunque las trayectorias de una y otra región en los años noventa eran incomparables, la propuesta era pensar una estrategia de desarrollo para que esto fuera posible en los años 2000. Debía diseñarse una estrategia alejada tanto del viejo desarrollismo como de la ortodoxia neoliberal partiendo desde una política macroeconómica mas bien convencional (un tipo de cambio alto, favorable a las exportaciones) combinada con políticas de infraestructura, políticas industriales selectivas y políticas comerciales (como por ejemplo las retenciones a las exportaciones agrarias en Argentina) adecuadas a dichos fines que tendían a su vez a una mayor integración regional. El Estado Neodesarrollista debía ser una burocracia eficiente y ágil, que no cayera en los déficits fiscales propios del viejo desarrollismo pero que no quedara reducido al mínimo posible que proponía el esquema neoliberal.

En la práctica, aquellos países que se propusieron llevar adelante estos planes tuvieron políticas y estrategias sumamente disímiles, que analizaremos a continuación.

\section{Brasil: el gobierno del PT, de Lula a Dilma}

El caso de Brasil es único por numerosas razones, ya que tiene la mitad del PBI de Sudamérica y es el único país con posibilidad de ser una potencia mundial, ya 
que tiene un desarrollo industrial único en relación al resto de los países de América Latina. Tras el período neoliberal de Fernando Henrique Cardoso (1994-2002), en el primer gobierno de Lula (2002-2006) la política neodesarrollista aparece lentamente ya que su política macroeconómica se ajustaba a la ortodoxia de una política monetaria rígida de la mano del presidente del Banco Central Henrique Meirelles, proveniente del Bank of Boston. Las políticas sociales fueron el punto de partida de una reducción de la desigualdad del ingreso y de los primeros intentos redistributivos en un país sumamente desigual como Brasil, llegando el Plan Bolsa Familia a cubrir a 50 millones de personas (25\% de la población). El alza del los precios de las materias primas comenzó a despuntar y favoreció a las exportaciones de soja, hierro y etanol, y a la acumulación de reservas internacionales; surgieron entonces nuevos planes de política industrial y de infraestructura, junto con un alineamiento internacional alejado de Estados Unidos, que se materializó en el mayor impulso a la integración latinoamericana y el rechazo en 2005 del proyecto del ALCA (Área de Libre Comercio para América Latina).

En el segundo gobierno de Lula (2006-2010) los planes neodesarrollistas asomaron en todo su esplendor, cuando se registró un boom del consumo y del crédito entre 2003 y 2008. Todo ello se vio potenciado desde 2009 con los descubrimientos de yacimientos del Pré-sal, un área de $160.000 \mathrm{~km}^{2}$ de petróleo en el lecho marítimo que podría convertir a Brasil en una potencia petrolera tardía y potenciar el neodesarrollismo (MERCADANTE, 2013).

Las principales iniciativas ligadas al Neodesarrollismo se basaron en políticas industriales y políticas de infraestructura, usando el BNDES (Banco Nacional de Desarrollo Económico y Social) como un banco de desarrollo nacional y regional, ya que junto con la CAF (Corporación Andina de Fomento) impulsó importantes proyectos en América del Sur. En las políticas industriales se destacó el papel de las empresas publicas (Petrobrás, BNDES, Banco do Brasil, Embrear, EMBRAPA, pero especialmente las dos primeras): el BNDES con el otorgamiento de enormes créditos subsidiados (con el objetivo de crear "campeones nacionales" como los chaebols de Corea del Sur) y Petrobrás mediante su actividad y sus inversiones con elevados requisitos de contenido nacional para sus proveedores. Los recursos fueron cuantiosos pero invertidos muchas veces de formas cuestionables, en sectores y actividades que no respetaban el medio ambiente y contra los reclamos de la población indígena. En cuanto a las políticas de infraestructura, la herramienta clave es la IIRSA (Integración de Infraestructura Regional Sud-Americana) que nació en el gobierno de Cardoso 
como un intento de expansión de Brasil sobre la región, en el contexto del avance del ALCA y que fue posteriormente incorporada a UNASUR para neutralizar al ALBA impulsado por Chávez (SANTOS, 2017). Se trató de un proyecto de grandes obras de infraestructuras, rutas, puntes, usinas, centros de acopio y distribución para lograr la interconexión de la región, las cuales históricamente se insertaba en el mercado mundial siempre a partir de puertos nacionales. El proyecto lo financió el BNDES y lo ejecutaron constructoras privadas brasileñas.

El sector agrícola también se vio impulsado por el auge de las materias primas. Las exportaciones brasileñas del sector agrícola pasaron de 25 mil millones de dólares en 2002 a 72 mil millones en 2008, convirtiendo a Brasil en el segundo mayor exportador de alimentos (carne bovina, pollo, azúcar, café y jugo de naranja) y materias primas (soja y hierro), superando a China y Canadá y por detrás de Estados Unidos. La producción de granos, cereales y oleaginosas aumento en un $51 \%$ en ese mismo período (MERCADANTE, 2013).

Sin embargo, la crisis financiera internacional mostró la exposición de Brasil al capital financiero global. En sus inicios 2007-2008 afectó poco a un Brasil con reservas internacionales cuantiosas por 240 mil millones de dólares, con presencia en el FMI, impulsando el G-20 y los BRICS. A su vez, hubo margen para las políticas del Programa de Aceleración del Crecimiento (PAC) que, de algún modo, expresaron el centro de las políticas neodesarrollistas. En 2008 las Políticas de Desarrollo Productivo, como parte decisiva de la PAC no fueron concebidas como un instrumento anticíclico pero fueron importantes para compensar la caída de la inversión privada con la naciente crisis financiera internacional (MERCADANTE, 2013).

El primer llamado de atención para el neodesarrollismo brasileño apareció desde 2009 con los efectos posteriores de la crisis financiera internacional, que produjo el cierre de mercados externos y una leve caída del PBI del 0,2\%. Pero se recuperó rápidamente al año siguiente con un aumento del $7 \%$ y permitió cerrar el período de Lula con un gran crecimiento y con unas reservas internacionales que pasaron de 16 mil millones de dólares en 2002 a 287 mil millones de dólares en 2010. Pero los déficits comercial y fiscal tendieron a aumentar y a desacelerar la economía en los años posteriores.

La crisis financiera internacional tuvo finalmente sus efectos en Brasil con suspensión de inversiones y amenazas de fugas masivas de capitales y con efectos recesivos inmediatos. Ya en 2010 algunos economistas señalaban que la subordinación del Estado brasileño a los intereses del capital rentista nacional e 
internacional, a la vez que otorgaba grandes subsidios y exenciones para el gran capital, llevaba a desplegar una política económica que comprometía la salida de la crisis y aumentaba peligrosamente la deuda externa, estimulaba procesos de regresión industrial. (SAMPAIO JUNIOR, 2010). Brasil se había tornado en palabras de Leda Paulani (2017, p. 31) una "plataforma internacional de valorización financiera" a lo largo de los gobiernos de Cardoso, Lula y Dilma. Además, al existir un enorme mercado de derivativos, la especulación sobre el tipo de cambio se volvió moneda corriente (PAULANI, 2017).

Los signos del desgaste de estas políticas se hicieron visibles en el primer gobierno de Dilma, que empezó a cultivar la relación con China como principal socio comercial de Brasil y primera fuente de inversión externa directa. La pérdida de popularidad de Dilma se observó en las manifestaciones callejeras de Junio de 2013 que luego serían ampliadas en 2014 antes del Mundial de Fútbol y terminaron condicionando tanto su reelección- que consiguió por escaso margen- como su segundo mandato.

\section{Argentina: el kirchnerismo y la "década ganada"}

En Argentina el período 2002-2005 es el período posterior a la gran crisis inaugurada con la insurrección de diciembre del 2001 que puso fin al neoliberalismo e inició una de las peores crisis económicas y políticas de su historia. La reactivación posterior a la gran crisis vino de la mano del gran aumento de los precios de los commodities, que favoreció a las exportaciones de todas las economías latinoamericanas y a la salida devaluacionista de la crisis, que permitió recuperar la rentabilidad, afianzar la reactivación 2002-2005 y estabilizar el crecimiento en 20062007 (BONNET, 2015). Ese período se caracterizó por un tipo de cambio alto y competitivo resultante de la mega devaluación que supuso la salida de la convertibilidad. Fueron también los comienzos de un superávit comercial importante- debido básicamente a la dificultad de importar- en el período 20022003. También en esos primeros años se dio un importante superávit fiscal, sobretodo a partir del no pago de los intereses de la deuda y a una inflación sumamente reducida, que no va a llegar al $10 \%$ en el periodo 2002-2005. El crecimiento fue habilitado por tarifas pesificadas y congeladas, un aumento leve de demanda, y cierta mejora de la industria basada en la recuperación de la capacidad instalada ociosa que había quedado del aparato productivo de la convertibilidad y un 
aumento de la inversión, sobre todo en el sector de la construcción, en el sector residencial y en la obra pública.

Una recuperación tan rápida estuvo en suspenso hasta que no dio un cierre -al menos provisorio- a la reestructuración de la deuda externa en 2005. Esa circunstancia fue un punto de quiebre y habilitó el período ascendente 2005-2008 (en 2005 se crece a más del 9\%, en 2006 al 8,4\%, en 2007 al 8\%) donde se hablaba del "modelo de crecimiento con inclusión social". Se iniciaba la discusión sobre "el modelo productivo" en simultáneo con el auge del neodesarrollismo en Brasil. Esta nueva industrialización sería la continuación de un proceso que se vio interrumpido en el año 1976 estando ahora dadas (para el kirchnerismo) las condiciones para retomarlo.

Ese segundo momento, el período 2005-2008, es el momento del mayor crecimiento económico hasta el "conflicto del campo", surgido del intento de aumentar las "retenciones" (impuesto a las exportaciones) agrarias, un momento clave del período pos-neoliberal en Argentina. Ese período es el mejor momento de la postconvertibilidad y de la acumulación de reservas internacionales. En 2001 las reservas habían caído a menos de 10 mil millones de dólares, en 2005 estaban cerca de los 30 mil y en el 2008, durante el conflicto del campo, alcanzaron los 46 mil millones de dólares. No obstante, a pesar del cambio de régimen político todavía no había un cambio estructural ni un auge industrial sino una recuperación de la capacidad instalada, que no estaba usándose de manera plena (PORTA y FERNÁNDEZ BUGNA, 2008). Había que generar inversiones. Pero es aquí donde aparece la reticencia inversora, producto en parte de la recuperación de los salarios reales (con muchas diferencias entre los trabajadores registrados y entre éstos últimos y los trabajadores "en negro") que se observa entre 2007 y 20012 (PIVA, 2015).

El alza de los precios internos comenzó a incidir sobre la inflación y el tipo de cambio, y por lo tanto redujeron la competitividad exportadora y el saldo comercial y de la balanza de pagos se volvió deficitario, lo que se ve agudizado con el reinicio de la fuga de capitales que sentará las bases para la instrumentación del denominado "cepo cambiario" a la disponibilidad de divisas. El problema de la industria es que era deficitaria en términos de divisas por los insumos importados y no hubo una política industrial adecuada a esa estrategia. (SCHORR y WAINER, 2015, SZTULWARK, 2015).

La idea de que esa mediación que propuso el gobierno entre las fracciones del capital era deliberadamente a favor de la industria y en contra de las otras fracciones es muy discutible. La propia salida del default reconstituye también la dinámica de la 
acumulación financiera -aunque estos sectores no adhirieron al programa del gobierno- por el solo hecho de reconstituir sus bases de acumulación. Después de la pesificación asimétrica el Estado pagó con bonos a los bancos puntualmente. Según Cibils y Allami las ganancias del sector financiero desde el 2005 (especialmente entre 2006 y 2009) y fueron incluso mayores que en los años ‘ 90 (CIBILS y ALLAMI, 2013).

Todo esto que todavía parecía ser una mediación compleja del Estado con diferentes fracciones del capital, que en eso términos se venía llevando bien, va a encontrar en 2008, con el conflicto agrario, un punto de no retorno. Siguió habiendo crecimiento y acumulación - en 2009 continuaba el crecimiento hasta el 2010-2011 - pero esa mediación compleja que pretendía realizar el kirchnerismo entre estas fracciones ya no va a estar convalidada desde los sectores dominantes. El kirchnerismo creyó poder conducir el proceso a favor de la fracción industrial mercado-internista en desmedro de las demás. Y las otras fracciones, dadas el contexto incierto post crisis fueron apoyando o al menos no la impugnaron. En el conflicto del campo esa relación se quebró a partir de la resistencia de los sectores rurales al aumento de las retenciones a las exportaciones agrarias.

El gobierno va a continuar teniendo la iniciativa política a pesar de la derrota en las elecciones legislativas de 2009 y termina en el 2011 con la reelección de Cristina Fernández de Kirchner. Entre 2010-2012 las tasas de inflación estuvieron por encima del $20 \%$ de manera permanente, y se asistió a una reticencia inversora evidente, un aumento de la fuga de capitales que tuvo un máximo en 2011 y al final de los superávit gemelos (superávit fiscal y de la balanza de pagos). Reaparece el problema de la restricción externa y la fuga de capitales lo que generó una señal de alarma habilitada por la utilización del "cepo cambiario" que se instaló ni bien fue electa Cristina Kirchner y que condicionó todo su segundo mandato con tasas de crecimiento débiles.

Mermaban las posibilidades de éxito de ese intento de mediación que era muy compleja ante esta fracción de capital agrario-exportador. Como señala Piva, el capital productivo orientado a la exportación tuvo la capacidad de convertirse en dominante al interior del "bloque en el poder" (PIVA, 2015, p. 34) aunque no emergía una articulación "por derecha” que pudiera disputarle el control sobre ese arbitraje al kirchnerismo. Al no conseguir apropiarse de una mayor parte de la renta agraria, intentó estimular la ganancia industrial para contrabalancear, algo que finalmente no sucedió. Pero hubo en cambio un "dejar hacer" a la renta minera, un aval a la renta 
financiera (a la que no se aplicaron restricciones ni impuestos) y cierta ignorancia respecto de los efectos de la renta inmobiliaria.

\section{Paraguay: Fernando Lugo y la interrupción de la hegemonia del Partido Colorado}

La historia económica y política de Paraguay esta condicionada por la persistencia del subdesarrollo durante todo el siglo XX y los regímenes políticos autoritarios, como la dictadura de 35 años encabezada por Alfredo Stroeesner, que se extendió desde 1954 hasta 1989. Relativamente aislado de los mercados internacionales, Paraguay mostraba una altísima concentración de la tierra, una estructura política autoritaria y una industrialización casi inexistente durante esas cuatro décadas, para un país pequeño que hoy cuenta con 7 millones de habitantes. La industria reconoce un crecimiento con las obras de construcción de las grandes represas hidroeléctricas para aprovechar el gran caudal del Rio Paraná.

Paraguay inició en 1973 la construcción de la represa Yaciretá, empresa hidroeléctrica binacional compartida con Argentina y luego en 1975 la represa de Itaipú, junto con Brasil, lo que supuso una inyección de dinero desde Brasil para la industria de la construcción y llevó un crecimiento de los sectores obreros hasta 1982. En esa década, Paraguay se endeudó siguiendo la línea de buena parte de las economías latinoamericanas y 1982, el año de la crisis de la deuda externa, coincide con el regreso al campo de los asalariados de Itaipú. La toma de tierras comienza a volverse un factor fundamental en la caída de Stroessner en 1989. La energía eléctrica es la única actividad de exportación junto con el algodón y la soja para un país que no tuvo ni siquiera un proyecto de sustitución de importaciones. Los terratenientes, los "barones de Itaipú" y los militares son los actores relevantes de un régimen paraguayo donde la corrupción continuaba presente aún en el período democrático de Andrés Rodríguez (1989-1993), Juan Carlos Wasmosy (1993-1998), Luis Gonzales Macchi (1999-2003) y Nicolás Duarte Frutos (20004-2008), las rebeliones militares (1996,1999, y 2000) estaban a la orden del día y convertían en 2005 a Paraguay en el tercer país mas desigual de América Latina (NICKSON, 2008).

Stroessner fue derrocado en un golpe de Estado de Andrés Rodríguez -que luego será electo- quien promovió reducciones arancelarias para el sector agroexportador (la soja transgénica es introducida tempranamente en 1989) y privatizó empresas públicas como las Líneas Aéreas Paraguayas. En la década de 1990 los gobiernos neoliberales mostraron un bajo crecimiento económico y enfrentaron 
numerosas crisis financieras entre 1995 y 2002, ya que se vieron afectados por la crisis en Brasil desde 1999 y la recesión de Argentina hasta su crisis en 2002.

La crisis política terminó con el bipartidismo del Partido Colorado y el Partido Liberal ya que en 2003 aparecen por primera vez seis partidos políticos en el Parlamento. Ese año comenzó también el auge de la soja, que permitió al agronegocio de capitales extranjeros, especialmente argentinos y brasileños, motorizando un crecimiento económico que habilitó la aparición de una nueva clase media. Pero los beneficios económicos de auge agrícola se concentraron en la elite de productores de soja, ganaderos y profesionales urbanos. La pobreza extrema aumentó del 15,5 al 19,4\% entre 2005 y 2007 (NICKSON, 2008).

El gobierno de Nicolás Duarte Frutos entre 2004 y 2008 arregló con el FMI una renegociación de la deuda externa y se vio beneficiado de la expansión de la soja, que desplazó definitivamente al cultivo del algodón y representaba el 30\% del PBI. Sin embargo, el descontento iba en aumento. El "obispo de los pobres", Fernando Lugo, encabezó en 2006 un movimiento de resistencia ciudadana a la reelección de Duarte Frutos y consiguió en acuerdo con el Partido Liberal crear la "Alianza Patriótica para el Cambio” y ganar las elecciones de 2008. Esto significó un quiebre institucional de enorme relevancia al poner fin a seis décadas de hegemonía del Partido Colorado, que nucleaba históricamente a representantes de los terratenientes, la iglesia y el ejército en un país que era ahora el cuarto productor mundial de soja. Lugo impulsó una reforma agraria pero muy tempranamente debió enfrentar los efectos de la crisis internacional.

El año 2010 es un año de enorme crecimiento económico, cercano al 10\%, y 2013 es aún mejor al alcanzar el $11 \%$ de crecimiento. Al tener un nivel de endeudamiento bajo de menos del 20\% del PBI, Lugo tenía margen para emitir bonos, promover la inversión externa directa y planificar la realización de obras de infraestructura mediante alianzas publico-privadas. Sin embargo, Lugo será destituido por razones poco claras, a través de un golpe institucional parlamentario en julio de 2012, luego de la masacre de Curuguaty, jaqueado en el Parlamento por el Partido Liberal y el Partido Colorado y por las movilizaciones patronales de la Unión de Gremios de la Producción (UGP) tras sólo cuatro años de gobierno. Los plantadores de soja "brasiguayos" contaban con el apoyo del gobierno brasileño y también se oponían a Lugo, (SANTOS, 2017, p. 22). Con una inversión externa de 400 millones de dólares en los sectores agrario y forestal el intento de frenar el avance del algodón transgénico parece haber condicionado el gobierno de Lugo. Luego de cinco 
años de interrupción, el partido Colorado volvió al poder de la mano del empresario tabacalero Horacio Cartes, que formó un gabinete de técnicos formados en Estados Unidos (CEOs), y seguirá cosechando los beneficios del auge de la sojización y del agronegocio.

\section{Uruguay: los gobiernos del Frente Amplio de Tabaré Vázquez al "Pepe" Mujica}

Uruguay recibió el impacto de la crisis del año 2002 de Argentina reflejada en una crisis económica y del sistema bancario -con un desempleo que alcanzaba el 17\%- entre 2002 y 2004. Apenas recuperándose de la crisis, el Frente Amplio (FA) llegó al poder de la mano de Tabaré Vázquez desplazando al Partido Colorado y al Partido Nacional y manteniéndose por tres períodos consecutivos e inauguró un período neodesarrollista en Uruguay, orientado a dinamizar el crecimiento económico en base a la inversión externa directa. Como señalan Santos et al. (2013), entre 2004 y 2011 la IED paso de 330 a 2700 millones de dólares, esto es, pasó de representar el 2\% al 6\% del PBI, lo que supone el doble del promedio para América Latina según la CEPAL (SANTOS et al., 2013).

Las expectativas en torno a un gobierno de izquierda eran altas dado los niveles de pobreza cercanos al 27\% en 2002 para una población de apenas 3,5 millones de habitantes y con un desempleo cercano al 10\%. El avance del neodesarrollismo se sostuvo en el boom agrícola iniciado en 2003 por el auge de los precios de las materias primas, y en el dinamismo de sectores como el forestal, las telecomunicaciones, la construcción y el transporte. En el período 2005-2012 cayeron fuertemente la pobreza (del 36 al 13\%) y la indigencia (del 4 al 0,5\%) aumentaron los salarios reales un $36 \%$, cayendo el desempleo a su mínimo histórico del 6\%, así como el subempleo pasó del 17 al 7\% y la informalidad del 38 al 28\%, lo que representa logros sumamente destacables. Sin embargo, el régimen de acumulación seguía sosteniéndose en la exportación de commodities de bajo valor agregado con una fuerte extranjerización de la propiedad y la producción en el sector agroindustrial al calor del auge del agronegocio forestal y sojero (SANTOS et al., 2013).

Las reformas fiscales de un sistema impositivo antiguo impusieron la supresión de numerosos impuestos, un notable aumento del gasto público social, con la creación del Ministerio de Desarrollo Social en 2005 y políticas focalizadas para la reducción de la pobreza y la indigencia (SANTOS et al., 2013). En las reformas del sector salud se destaca el nuevo Sistema Nacional Integrado de Salud (SNIS) que 
afilio a 1,5 millones de uruguayos. En cuanto a la educación el presupuesto aumentó notablemente a un $4,5 \%$ del PBI.

El inicio del gobierno de José "Pepe" Mujica lo encontró con un bajo nivel de desempleo del 5,5\% y con una mejor relación con el gobierno argentino de Cristina Fernández de Kirchner. La orientación del gobierno pasó por apostar por la minería con la aprobación de un nuevo Código Minero en diciembre de 2010, al que se oponían numerosos productores rurales. A las exportaciones tradicionales de carne, soja, arroz y celulosa se agrega el hierro. Numerosos proyectos mineros se proponen para el período 2010-2013 como el proyecto Minero Aratirí previsto para la explotación del hierro por 12 años (unos 18 millones de toneladas al año) para abastecer a la siderurgia de China por parte de la empresa india Zamin Ferrous, lo que suponía una inversión de 3000 millones de dólares, la mayor inversión externa de la historia uruguaya. También se preveía el desarrollo de proyectos de infraestructura como un puerto de aguas profundas lo que generó numerosas luchas contra la minería de cielo abierto y el agronegocio (ELIZALDE, MENÉNDEZ y SOSA, 2013).

La actividad bancaria off shore se verá complementada con desarrollos de "enclaves informacionales" bajo el encuadre de las zonas francas que gozaban de excepciones fiscales y aduaneras para el outsourcing de servicios informáticos, de atención a clientes y servicios financieros (FALERO, 2013). Esas actividades se acompañaron de desarrollos inmobiliarios para explotar la renta urbana así como la proliferación de otras actividades rentísticas, pero en el marco de gobiernos progresistas.

Como uno de los socios pequeños del MERCOSUR mantenía vínculos muy estrechos con la economía de Argentina y especialmente con Brasil, con quien registraba un déficit comercial enorme, de casi 1.000 millones de dólares. La relación con Argentina va a deteriorarse a raíz de un conflicto ambiental alrededor de la instalación de la pastera Botnia, de capitales finlandeses, sobre el río Uruguay. El interés de Uruguay en aumentar la inversión externa y el empleo, vinculado a la construcción y puesta en marcha de la planta, chocaba con los efectos sobre el ambiente derivado del propio funcionamiento de la pastera, altamente contaminante. El conflicto entre Argentina y Uruguay condicionó las relaciones bilaterales entre ambos países durante los gobiernos de Tabaré y Kirchner. 


\section{Efectos sobre la integración regional y los vínculos con el resto de América Latina}

El Mercado Común del Sur (MERCOSUR) que había despegado finalmente en los años 90 en el marco del "regionalismo abierto" fue definido en el Tratado de Asunción de 1991 como un Mercado Común, pero de hecho es una Unión aduanera formada por Argentina, Brasil, Paraguay y Uruguay. Como parte de la institucionalidad perteneciente a la ofensiva neoliberal (KAN, 2011) entra en vigor en 1995 luego de comprometerse a definir una política comercial común, a eliminar barreras no arancelarias, a llevar adelante un programa de desgravación automática y secuencial para todo el comercio intrazona y a la definición de un Arancel Externo Común (AEC) Algunos sectores importantes (como el sector automotriz o azucarero) quedaron excluidos del programa general y tendrán un acuerdo específico de intercambio compensado, por eso se trata de una Unión Aduanera "imperfecta" (PORTA, GUTTI y BERTONI, 2012, p. 292-297).

El espacio económico integrado debía servir para mejorar la inserción de la región en la economía mundial por medio de la negociación conjunta de los países miembros con el resto del mundo. El bloque había logrado establecer un fuerte aumento del comercio al interior del mismo entre 1995 y 2000 de casi un $70 \%$ pero no había podido morigerar ni tener relevancia en las crisis del real de 1999 ni en la crisis de diciembre 2001 en Argentina. Pasar de una zona de libre comercio a una unión aduanera y de ésta a un mercado común suponía desafíos institucionales y prácticas gubernamentales que distaban mucho de las decisiones habituales de los países y de los órganos del Mercosur. No había mecanismos de solución de controversias y predominaban esquemas intergubernamentales más que supranacionales (KAN y PASCUAL, 2011), y, más precisamente, los oficios de la diplomacia "presidencial” del eje Argentina-Brasil. Ello ataba el futuro del Mercosur al de sus socios principales a tal punto que Uruguay y Paraguay reclamaban compensaciones y amenazaban permanentemente con salir del bloque por tratarse de las economías mas pequeñas y menos beneficiadas del proceso (BOTTO, 2015).

Pero desde 2003 en adelante se asistió a una revitalización del Mercosur (KAN, 2014) con el compromiso político de los gobiernos de Brasil y Argentina de avanzar hacia una profundización de la integración e ir mas allá de una mera "integración comercialista" y desde allí poder negociar como bloque frente al ALCA y la UE (KAN, 2014, p. 234-310). La política exterior de Brasil y Argentina intentó despegarse del alineamiento con Estados Unidos e incluso se trabaron las negociaciones del ALCA en el marco del fracaso de la Ronda de Doha de la OMC en 
septiembre de 2003, plantearon el rechazo al ALCA y desde allí articularon el crecimiento del proceso ante el avance de las políticas intervencionistas y neodesarrollistas en tres de los cuatro países.

Brasil asocia este avance en sus relaciones exteriores como parte de su estrategia neodesarrollista de crecimiento acelerado, con políticas sociales y desarrollo de la ciencia y tecnología. La creación de UNASUR en 2008, con una impronta más política que comercial o económica va en la misma dirección de "sudamericanizar" su política regional (COMINI, 2016), aunque este también propone proyectos de infraestructura financiado por el BNDES y la Corporación Andina de Fomento (CAF) (MERCADANTE, 2013). Para Santos (2017) en cambio, la resonancia regional de Unasur y su adhesión al IIRSA mostraba los límites de la integración regional de los gobiernos sudamericanos al pretender neutralizar las lógicas de la Alianza Bolivariana de los Pueblos de América Latina (ALBA) liderada por Chávez (SANTOS, 2017).

Los años 2003-2006 se caracterizaron por la recuperación de la integración y la reactivación del comercio intrazona (PORTA, GUTTI y BERTONI, 2012). A su vez, las inversiones de capitales intrazona del Mercosur serán casi exclusiva tarea de la internacionalización de capitales brasileños.

Las asimetrías estructurales fueron significativas dadas la gran heterogeneidad de los cuatro miembros y del peso de las políticas de promoción de Brasil en relación a los otros países, como los programas de promoción sectoriales (PORTA, GUTTI y BERTONI, 2012, p. 361). Como señala Comini, Brasil quería extenderse hasta América del Sur pero Argentina preferiría proyectarse aún más lejos al espacio latinoamericano, incluyendo a otros países relevantes como México para contrabalancear el poder de Brasil (COMINI, 2016). En 2003 se incorporaron Bolivia y Perú como Estados Asociados, como era Chile, y luego en 2005 lo harán Colombia, Ecuador y Venezuela, esta última como miembro pleno (COMINI, 2016). En 2006 se generaron tensiones entre Brasil y Bolivia por la nacionalización de hidrocarburos al inicio del gobierno de Evo Morales, pero Lula adoptó una posición conciliadora mediada por la correspondiente indemnización a Petrobrás (MERCADANTE, 2013).

Sin embargo, un proceso que condicionará el desempeño de la integración en toda América Latina será el impacto del crecimiento de China. En los años 2000 la relación comercial de China con América Latina era muy poco relevante pero de a poco se fue convirtiendo en el mayor importador de commodities del continente (la 
región aumentó su participación del 2 al $10 \%$ de las importaciones chinas entre 2000 y 2011), tanto del sector primario como del sector minero. La creciente demanda china permitió el relanzamiento de las materias primas de la región y la ilusión de organizar un programa de desarrollo con base agrícola, agroindustrial o minero, aunque pudiera afectar a las exportaciones industriales brasileñas o argentinas en el continente.

En 2008, en los inicios de la crisis internacional, China reconoció el carácter estratégico de su relación con América Latina en su Libro Blanco (SLIPAK, 2014). En 2013 sólo cinco productos primarios representan el 75\% de las exportaciones regionales a China (centralmente soja desde Brasil, Argentina y Paraguay; hierro desde Brasil; cobre desde Chile y Perú y petróleo desde México, Venezuela, Ecuador y Colombia). Desde 2009 comenzó a aumentar su inversión externa directa en minería, en el sector agrícola, en infraestructura e hidrocarburos y a realizar préstamos externos a los gobiernos de Brasil, Argentina, Venezuela y Ecuador (SLIPAK, 2014).

La creación en 2011 de la Alianza del Pacífico (AP) como una Zona de Libre Comercio entre Chile, Perú, Colombia y México va a suponer un desafío a la UNASUR y a las dinámicas de la integración regional, y en consecuencia, a este crecimiento del Mercosur (COMINI y FRENKEL, 2014). Son países que crecen, involucran entre el 40-50\% del PBI, las inversiones externas y el comercio exterior de América Latina, y son proclives a la integración por la vía de TLC bilaterales. Tienen, además, TLC con Estados Unidos ya que necesitan mucho mas del mercado norteamericano que los países del Mercosur (MALAMUD y CASTRO, 2009) у ya desde 2013 reciben más IED que el Mercosur (TURZI, 2014). Los proyectos para una "convergencia" comienzan a proliferar en 2015, cuando el Mercosur elevó a la Alianza del Pacífico un Plan de Acción que incluía la profundización de los acuerdos de complementación económica (ACE) ya firmados y suponen mas bien una aproximación del Mercosur a las reglas de la AP que a la inversa. (TURZI, 2014).

\section{Segundo momento: el ciclo descendente (2013-2015) y el renovado avance neoliberal (2016-2018) en América Latina}

La estrategia de "cambio de la matriz productiva" encabezada por los países del Mercosur, sinónimo de expansión de la demanda agregada, reducción de la pobreza y de absorción del desempleo fue acompañada por el contexto internacional favorable para las economías en desarrollo. Cuando las condiciones internacionales empeoraron, en un contexto de crisis financiera global sólo menguada por el 
crecimiento de China, se hicieron evidentes los límites de estos procesos en los diferentes países del Mercosur.

Con diferencias importantes entre ellos, Argentina, Brasil y Uruguay van a ver afectados el vigor de esa estrategia y van a evidenciar sus debilidades estructurales y van a habilitar los cuestionamientos políticos y las derrotas electorales de algunos de estos regímenes. Como analizaremos, el resurgimiento de proyectos neoliberales está a la orden del día en los países del Mercosur y en todo el continente latinoamericano.

\section{Brasil: recesión económica, crisis política y caída de Dilma Rousseff}

Tras las enormes manifestaciones de 2013 y una gran pérdida de popularidad en el segundo período de gobierno iniciado en 2014, Dilma Rousseff había ganado su reelección por muy poco margen y había quedado con un Congreso muy desfavorable e implementando un ajuste fiscal que le quito aún más apoyo. Su gobierno se fragilizó y no pudo, no supo o no quiso alterar los intereses de las clases dominantes en sus trece años en el poder. Luego de dos años de recesión desde 2014 - ese año el PBI apenas aumentó 0,5\% y cayó 3,5 \% en 2015 y 3,6\% en 2016 -, con aumentos del desempleo y de la inflación, terminó con el "impeachment" de Dilma el 31 de agosto de 2016 por desmanejo de las cuentas publicas e irresponsabilidad fiscal, un derrocamiento parlamentario forzado en un contexto de déficit fiscal del 9\% PBI, (solo detrás de USA y China), desempleo del 13\%, aumento de la deuda y avance de causas de corrupción (Operación Lava Jato/caso Odebrecht).

Michel Temer reemplazó a Rousseff y tomó el proyecto de la derecha, siguiendo la retórica del ajuste inexorable y condicionando la inversión social a la inflación. Produjo numerosos cambios de ministros, avanzó el programa de Privatizaciones (Aeropuertos, Eletrobrás), buscó reducir beneficiarios del programa Bolsa Familia y consiguió aprobar una Reforma Laboral en julio de 2017 para debilitar a los sindicatos y procurar una reforma provisional.

En 2018, Temer decretó la intervención militar en Río de Janeiro y se produjo la decisión del Tribunal Superior de Justicia de habilitar el encarcelamiento de Lula, bajo amenaza de golpe militar, lo que mostró un horizonte preocupante con el triunfo del derechista Jair Bolsonaro en las elecciones de octubre de 2018.

\section{Argentina: el desgaste del "modelo" y el triunfo electoral de Mauricio Macri}


El año 2013 en Argentina es un año de bajo crecimiento, caída de reservas y alta inflación que pone en alerta al segundo gobierno de Cristina Fernández. La devaluación en enero de 2014 responde a la gran diferencia del dólar oficial con el paralelo (el dólar blue se estaba yendo al doble del precio oficial). Frenar ese avance del dólar blue en enero de 2014 con una devaluación y con suba de la tasa de interés del $30 \%$ da comienzo a un ciclo recesivo del cual nunca se volvió a salir. Aparecen controles cambiarios mucho más fuertes después del 2011 así como el crecimiento del dólar paralelo, el aumento de las importaciones de energía y la necesidad de búsquedas de capitales. Esto condujo en 2015 al gobierno al intento de los pagos a los acreedores del Club de París y terminar así con la reestructuración de la deuda externa que había quedado pendiente, lo que lleva al conflicto con los fondos "buitres" tenedores de deuda. El período 2011/2015 fue de alternancia entre crecimiento bajo y caídas del PBI y terminó con la derrota electoral del kirchnerismo a manos de Mauricio Macri y su proyecto neoliberal actualizado a las nuevas circunstancias, que plantea un giro para todo el continente sudamericano.

De este estancamiento el macrismo va a pretender salir ajustando las cuentas públicas y fomentando la inversión externa, algo que por ahora no ha sucedido en los tres años que lleva de gobierno (2015-2018). El gobierno neoliberal liberó el tipo de cambio, (que subió de 12 a 20 pesos en los primeros dos años y en 2018 alcanzó los 40 pesos) con lo que se produjo un aumento exponencial del dólar y una megadepreciación del peso, actualizó las tarifas de los servicios públicos a los niveles del dólar y aumentó la deuda externa a niveles inéditos (de 240.000 a 350.000 millones de dólares entre comienzos de 2016 y fines de 2018). La corrida cambiaria de 2018 amenazaba las reservas internacionales del Banco Central y el gobierno decidió recurrir al FMI en su rescate, que se comprometió a aportar unos 57.000 millones de dólares (elevando la deuda externa que ya supone un 95\% del PBI cuando en el comienzo del macrismo era del 53\%) y condicionó su asistencia a la profundización del ajuste, que ya había sido iniciado por el macrismo. Los años 2017 y 2018 fueron de caída del PBI, gran aumento de la inflación y el desempleo sin que se vean señales de recuperación a un año de las elecciones presidenciales de 2019. Con un endeudamiento interno y externo más que preocupante el gobierno mantiene la iniciativa política sobre la base de acusaciones de corrupción del gobierno kirchnerista.

\section{Paraguay: Horacio Cartes y la consolidación del "modelo sojero"}


El período de Horacio Cartes en el poder (2013-2018) es un período de crecimiento basado en el modelo sojero, cuyo éxito es innegable. El PBI de 30.000 millones de dólares se triplicó en veinte años desde 1995. El crecimiento de los quince años de la sojización (2003-2018) se produjo sin mayor inclusión social pero con la cuasi-duplicación de la clase media y una reducción de la pobreza que pasó del $50 \%$ en 2003 al $28 \%$ en 2018.

Paraguay es un paraíso financiero para capitales de Argentina y Brasil. Numerosos empresarios brasileños invierten también en "maquilas" para la producción de bienes de consumo destinados a Brasil. La sojización apenas necesita mano de obra dada la automatización de las plantaciones pero contribuyó al desarrollo de infraestructura para la exportación y al boom inmobiliario en Asunción, en manos de capitales argentinos, brasileños y españoles. Según Jorge Gonzáles (2016) entre 2013 y 2016 el acaparamiento de las tierras indígenas y campesinas por todos los medios, legales e ilegales, pacíficos y violentos, produjo un aumento de la superficie sembrada de soja y una mayor deforestación, consolidando el modelo sojero frente al de la agricultura familiar campesina. Muchas familias campesinas terminaron vendiendo sus lotes a empresarios sojeros -sobre todo brasileños - bajo la presión de fumigaciones, amedrentamientos y ofrecimientos de compra de tierra (GONZÁLES, 2016).

En 2018 Mario Abdo Benítez, el candidato de Cartes, ganó la interna del Partido Colorado y luego las elecciones presidenciales -por escaso margen- a la alianza formada por el Partido liberal y por el ex presidente Lugo, por lo que se espera la continuidad en la expansión del modelo sojero.

\section{Uruguay: el retorno de Tabaré Vazquez y los dilemas no resueltos del Frente Amplio}

Desde 2003, luego de evitar el temido default de la deuda externa gracias a un préstamo de Estados Unidos, Uruguay inició uno de los períodos de mayor crecimiento económico de su historia al calor del auge de los precios de las commodities y de las inversiones externas. Con un fuerte crecimiento del PBI, de la inversión externa y las exportaciones, así como una significativa mejoría en la distribución del ingreso, un descenso del desempleo y un importante reducción de la pobreza (del 39,9\% en 2004 al 9,7\% en 2014) e indigencia (del 4,7 al 0,3\% en el mismo período) (CAETANO, 2017). 
El nuevo mandato de Tabaré Vázquez (2014-2018) supuso dar marcha atrás con algunas decisiones de Mujica y generar algunas tensiones en el Frente Amplio. En materia de relaciones exteriores, por ejemplo, el gobierno impulsó un TLC con Chile, único país de Sudamérica que no forma parte como miembro pleno de alguno de los bloques económicos y que firma habitualmente estos tipos de acuerdos, y que ya fue aprobado por el parlamento uruguayo.

El clima de descontento comienza a sentirse en 2015 con un conflicto social en ascenso, marcado por varios paros generales de los trabajadores del Plenario Intersindical de Trabajadores-Convención Nacional de Trabajadores (PIT-CNT) realizados en el segundo gobierno de Tabaré en reclamo de mejoras salariales (CAETANO, 2017). El contexto regional y los múltiples descontentos permiten dudar o ponen en peligro la continuidad del gobierno progresista en las próximas elecciones de 2019.

\section{Impactos sobre la integración regional latinoamericana (2013- 2018)}

El avance de la Alianza del Pacífico y la crisis de UNASUR contribuyen a cuestionar el proyecto brasileño de consolidar la integración sudamericana y al propio MERCOSUR incluso desde el interior de Brasil. Desde 2015, a caballo de la crisis en Brasil y Argentina, se asiste en el Mercosur a una contracción de la actividad económica y a una reducción de la inversión externa directa y no se observa una tendencia hacia los encadenamientos productivos entre países que pudieran provocar un mayor intercambio. Avanza desde 2016 el resurgimiento de un acuerdo entre el Mercosur y la Unión Europea (5 países con 27 países tomados en conjunto), que había iniciado en el año 2000 pero se había suspendido en 2004 luego del fracaso de la ronda Doha de la OMC y porque el Mercosur exigía remover barreras arancelarias y subsidios agrícolas (la Unión Europea ya viene negociando con otros países latinoamericanos acuerdos de menor envergadura). Luego de este empantanamiento, en 2015 Brasil (aún en el gobierno de Dilma), Paraguay y Uruguay van a buscar poder negociar por separado tratados bilaterales con otros países como China, no sólo con la Unión Europea, algo que sería contrario al Mercosur. Pero Argentina también parece inclinarse, con Macri, a favor de la "flexibilización" del Mercosur, avanzando en el camino hacia las negociaciones bilaterales.

La posición de los gobiernos progresistas en el ocaso de sus mandatos no es una posición muy firme a favor de la profundización de la integración y es difícil que avancen alternativas viables si cada país negocia por separado. 


\section{Cierre del ciclo pos-neoliberal y balance critico del neodesarrollismo}

El neodesarrollismo de los años 2000 encarna el espíritu del viejo desarrollismo pero incluyendo sectores que en principio se encontraban fuera de su alcance. El neodesarrollismo va a incluir al sector agrario y a la minería, además de la industria, como objeto de políticas públicas específicas.

Lo que estos enfoques no pueden advertir es que a comienzos del siglo XXI la situación de la economía mundial es completamente distinta del período correspondiente a los años dorados del capitalismo de posguerra, donde se concibieron los diagnósticos desarrollistas. En la actualidad la industria no puede cumplir con las promesas de la producción en masa con pleno empleo y consumo masivo del período keynesiano - benefactor. Se produjo una reestructuración de la gran fábrica fordista que condujo a la fragmentación de la producción a escala global junto con una transformación de la lógica misma de la valorización del capital. La valorización del trabajo cognitivo, la apropiación privada del conocimiento socialmente construido es el anuncio de un capitalismo que va acentuar la emergencia de un trabajo inmaterial y la emergencia de un capitalismo cognitivo y financiarizado en desmedro del clásico capitalismo industrial y donde la acumulación a escala global y la mundialización del capital se muestra en línea con la hipertrofia del capital financiero (MÍGUEZ, 2014 y 2016).

El crecimiento del período pos-neoliberal latinoamericano antes que en los logros de sus gobiernos debe buscarse en los movimientos de las grandes masas de capitales financieros especulativos que en su fuga hacia delante abandonaron los países centrales en busca de nuevas oportunidades de valorización que facilitaron liquidez, algunas inversiones directa y el boom de los precios de los commodities al refugiarse en las materias primas. El neodesarrollismo se apoya sobre logros importantes pero efímeros y reversibles como la lenta recuperación del poder adquisitivo de los salarios, una ligera mejora en la distribución de la renta y un boom de consumo financiado por el endeudamiento de las familias (SAMPAIO JUNIOR, 2012). Debemos diferenciar los objetivos de la propuesta neodesarrollista en la teoría de la práctica efectiva de los gobiernos latinoamericanos en los años 2000 que en la práctica concreta fueron mucho más ambivalentes.

Al igual que en otros países de América Latina la persecución política y judicial a los funcionarios del período posneoliberal señala la consolidación del ascenso de nuevas derechas que retoman el proyecto neoliberal suspendido a 
comienzos de los años 2000. En parte, la facilidad con que se imponen estas nuevas coaliciones permite poner en duda la obtención de una verdadera reversión del neoliberalismo por parte de los gobiernos "progresistas". Al margen del carácter conservador de los mismos, la rapidez del avance refleja los límites de muchas de las iniciativas que de forma más pomposa y retórica que real anunciaban el final definitivo del neoliberalismo.

- Pablo Míguez é Doutor em Ciências Sociais pela Universidad de Buenos Aires (UBA). Pesquisador do CONICET-Universidad de San Martín (UNSAM), Pesquisador e Professor da Universidad Nacional de General Sarmiento (UNGS) e Professor da Universidad de Buenos Aires (UBA). E-mail: pablofmiguez@gmail.com.

\section{Referências}

BONNET, Alberto. El kirchnerismo. La insurrección como restauración. Buenos Aires: Prometeo, 2015.

BOTTO, Mercedes. La integración regional en América Latina: Quo Vadis? El Mercosur desde una perspectiva sectorial y comparada. Buenos Aires: Eudeba, 2015.

CAETANO, Gerardo. ¿Milagro en Uruguay? Apuntes sobre los gobiernos del Frente Amplio. Nueva Sociedad, n. 272, p. 13-28, 2017.

CIBILS, Alan; ALLAMI, Cecilia. Financialisation vs. Development Finance: the Case of the PostCrisis Argentine Banking System. Revue de la Régulation. (En ligne), n. 13, p. 1-18, Spring 2013.

COMINI, Nicolás. Suramericanizados. La Integración regional desde la Alianza al Kirchnerismo. Buenos Aires: Ediciones Universidad del Salvador, 2016.

COMINI, Nicolás; FRENKEL, Alejandro. Una Unasur de baja intensidad. Nueva Sociedad, n. 250, p. 58-77, 2014.

ELIZALDE, Lucía; MENÉNDEZ, Mariana; SOSA, María Noel. Cronología sobre el conflicto minero en Uruguay 2010-2013. Contrapunto, n. 2, p. 47-70, 2013.

FALERO, Alfredo. El desarrollo de enclaves y la ilusión del desarrollo. Contrapunto, n. 2, p. 33-46, 2013.

GONZÁLES, Jorge. Paraguay: el "nuevo rumbo" apura el acaparamiento de tierras campesinas e indígenas al cumplir sus tres ańos. Informe especial, n. 5, p. 1-8, 2016.

KAN, Julián. La integración desde arriba. Los empresarios argentinos frente al MERCOSUR y el ALCA. Buenos Aires: Ediciones Ciccus-Imago Mundi, 2014. 
Neoliberalismo e integración entre Argentina y Brasil en los orígenes del MERCOSUR. Desde la Declaración de Iguazú de 1985 hasta la crisis de 1999. Densidades: Revista de Integración regional, n. 6, p. 35-48, 2011.

KAN, Julián; PASCUAL, Rodrigo. La política exterior argentina post 19 y 20 de diciembre (La Autoconvocatoria No al ALCA y las negociaciones gubernamentales por el ALCA). Revista Herramienta, n. 46, p. 97-107, 2011.

MALAMUD, Andrés; CASTRO, Pablo. ¿Integración o fragmentación? Política, seguridad, energía y comercio. In: PINTO, Julio (Comp.): Entre la integración y la fragmentación regional. El desafío político de nuestro tiempo. Buenos Aires: Eudeba, 2009.

MERCADANTE, Aloizio. Brasil. De Lula a Dilma (2003-2013). Buenos Aires: Clave Intelectual, 2013.

MÍGUEZ, Pablo. El desarrollo y los bienes comunes en América Latina. Una mirada desde las tesis del Capitalismo Cognitivo. In: FÉLIZ, Mariano; LÓPEZ, Emiliano; GARCÍA, Matías (Coords.). Desarmando el Modelo. Desarrollo, conflicto y cambio socia tras una década de neodesarollismo en Argentina. Buenos Aires: El Colectivo, 2016.

. Del General Intellect a las tesis del "Capitalismo Cognitivo": aportes para el estudio del capitalismo del siglo XXI. Bajo el Volcán, Revista de Sociología de la Benemérita Universidad Autónoma de Puebla, año 13, n. 21, p. 27-57, 2014.

NICKSON, Andrew. Una oportunidad para Paraguay. Los desafíos de Fernando Lugo. Nueva Sociedad, n. 216, p. 4-16, 2008.

PAULANI, Leda. Não há saída sem a reversão da financeirização. Estudos Avançados, v. 89, n. 31, p. 29-35, 2017.

PIVA, Adrián. Economía y política en la Argentina kirchnerista. Buenos Aires: Batalla de Ideas, 2015.

PORTA, Fernando, GUTTI, Patricia; BERTONI, Ramiro. Integración económica. Quilmes: Universidad Nacional de Quilmes, 2012.

PORTA, Fernando; FERNÁNDEZ BUGNA, Cecilia. El crecimiento reciente de la industria argentina. Cambio de régimen sin cambio estructural. Realidad Económica, n. 233, p. 17-48, 2008.

SAMPAIO JUNIOR, Plinio de A. Desenvolvimentismo e neodesenvolvimentismo: tragédia e farsa. Serviço Social \& Sociedade, n. 112, p. 672-688, 2012.

. O Brasil não é maior do que a crise. Jornal dos economistas, n. 255, out. 2010. Disponível em: $\quad<$ http://www.scielo.br/scielo.php?script=sci_nlinks\&ref=000105\&pid=S0101$6628201200040000400023 \& \operatorname{lng}=$ en>. Acesso em: 3 nov. 2018.

SANTOS, Carlos; NARBONDO, Ignacio; OYHANTCAVAL, Gabriel; GUTIÉRREZ, Ramón. Seis tesis urgentes sobre el neodesarrollismo en Uruguay. Contrapunto, n. 2, p. 13-32, 2013.

SANTOS, Fabio Luis Barbosa dos. Seis hipótesis para ler a coyuntura brasileira. Cuadernos IHUideias, v. 15, n. 263, p. 1-26, 2017.

SCHORR, Martín; WAINER, Andrés. Algunos determinantes de la restricción externa en Argentina. Márgenes, Revista de Economía Política, n. 1, p. 55-80, 2015.

SLIPAK, Ariel. América Latina y China: ¿cooperación Sur-Sur o "Consenso de Beijing"? Nueva Sociedad, n. 250, p. 102-113, 2014.

SZTULWARK, Sebastián. El kirchnerismo y la concepción del cambio estructural. Márgenes, Revista de Economía Política, n. 1, p. 81-94, 2015. 
112 | Pablo Míguez

TURZI, Mariano. Asia y la ¿(des)integración latinoamericana? Nueva Sociedad, n. 250, p. 78-87, 2014.

Texto recebido em 09 de janeiro de 2019. Aprovado em 23 de maio de 2019. 